\title{
EDITORIAL
}

\section{A crowded calendar}

\author{
The preponderance of global public health campaigns reflects the ongoing importance of \\ the need to raise awareness of infectious diseases, and their devastating effects.
}

Did you know that 5 May was Hand Hygiene Day? Or that May is not only Hepatitis Awareness Month but also Lyme Disease Awareness Month? Did you miss the fact that April was STD Awareness Month and that it also featured World Immunization Week (20-27 April 2013), World Meningitis Day (24 April) and World Malaria Day (25 April)? In fact, you can find a campaign day associated with infectious diseases in most weeks of the year, not to mention those campaigns which last a week or even a calendar month.

What purpose do such campaign events serve? Obviously, the main aim is to use a designated day to attract media attention to a particular infectious disease and then use this media attention to raise awareness in the general public. A well-organized press campaign packed with facts and figures describing (mostly) rising infection and mortality rates and the staggering number of disability-adjusted life years (DALYs) lost, along with human interest stories and some background details of the disease and the causative agent, is a necessity these days to capture precious column (or screen) inches. For those who work in microbiology and infectious diseases, the burden of infectious diseases is not news, of course. But it is naive to assume that this is general knowledge and that the public do not need reminding of the still devastating effects of infectious diseases, particularly in the developing world. Campaign events also offer an opportunity to engage with local, national and international stakeholders, providing a focus for fund-raising and outreach efforts. To capitalize on the increased press attention, major policy shifts or funding initiatives are also often timed to coincide with a campaign day.

Not surprisingly, some of the largest global health campaign days are World TB Day (24 March), World Malaria Day (25 April) and World AIDS Day (1 December). The first World TB Day was held on 24 March 1982 to commemorate the one hundredth anniversary of the discovery of Mycobacterium tuberculosis by Robert Koch. Initially organized by the International Union Against Tuberculosis and Lung Disease, it gained WHO support in 1996. This year's World TB Day was the second in a 2-year campaign entitled 'Stop TB in my lifetime', which urges individuals to become advocates for increased commitment, visibility and funding for tuberculosis (TB) research and treatment. It was preceded by the signing of the Swaziland Statement by representatives of the governments of South Africa, Swaziland, Zambia and Zimbabwe, along with representatives of agencies such as the World Bank, the Joint United Nations Programme on HIV/AIDS (UNAIDS) and the Stop TB Partnership. The statement marked the fact that there are now fewer than 1,000 days to achieve the Millennium Development Goal of cutting TB-related mortality (including that associated with HIV) by $50 \%$ by 2015 , and pledged a recommitment to achieving this goal, along with new funding initiatives.

World AIDS Day has been a fixture in the calendar for 25 years and is a high-profile event that played a major part in popularizing the red ribbon as a symbol of HIV/AIDS awareness. The theme of World AIDS Day for 2011-2015 is 'Getting to zero', meaning a focus on achieving zero discrimination, zero new HIV infections and zero HIV-related deaths. World Malaria Day started in only 2007 , so as yet has some way to go to match the media coverage given to the TB and AIDS events, but the 2013 event, which had the general theme 'Invest in the future: defeat malaria, was profiled in many mainstream media outlets.

Other campaign days, such as Hand Hygiene Day, focus on a useful health message. Rather than being targeted at the general public, Hand Hygiene Day is an annual initiative aimed directly at health care workers worldwide and provides a useful opportunity to remind them of the importance of hand-washing, a simple but potentially life-saving measure. The campaign is focused on WHO hand-washing guidance and promotes the idea that health care workers should clean their hands thoroughly at their 'five moments for hand hygiene': before touching a patient; before clean or aseptic procedures; after exposure to, or risk of exposure to, body fluids; after touching a patient; and after touching patient surroundings.

There are, of course, countless other global health campaigns out there, all vying for your attention in print and online as well as taking advantage of social media tools. At times, it may seem that the proliferation of campaigns has been such that there are now too many. However, with funding being squeezed and the burden of infection for many diseases increasing, it is not surprising that patient groups, researchers and campaigners are keen to have their voices heard. So yes, perhaps the calendar is now a little crowded, but if you can, please use the opportunity to pass the message on. 